\title{
Effect of a Multicomponent Sleep Protocol on Sleep Quality in Conscious Patients in the Intensive Care Unit
}

\section{Yoğun Bakım Ünitesindeki Bilinçli Hastalarda Çok Bileșenli Uyku Protokolünün Uyku Kalitesine Etkisi}

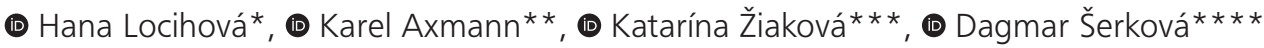 \\ *AGEL Research and Training Institute, Prostějov, Department of Anaesthesiology and Resuscitation and Intensive Care Medicine,Hospital Valašské \\ Meziríćí, and Secondary Nursing School AGEL, Ostrava, Czech Republic \\ * Department of Anaesthesiology and Resuscitation and Intensive Care Medicine, University Hospital Olomouc and Faculty of Medicine and Dentistry, \\ Palacky University, Olomouc, Czech Republic \\ ***Department of Nursing, Jesseniuss Faculty of Medicine in Martin, Comenius University, Bratislava, Slovak Republic \\ ****Department of Nursing and Midwifery, University of Ostrava, Faculty of Medicine, Czech Republic and Interdisciplinary Intensive Care Unit, Hospital \\ Nový Jičín, Ostrava, Czech Republic
}

\begin{abstract}
Objective: Sleep disruption is common in patients admitted in the intensive care unit (ICU), and it is associated with various negative effects. This study aimed to investigate whether the implementation of a multicomponent sleep protocol improved the quality of sleep, both subjectively (assessed with a questionnaire) and objectively (measured using actigraphy).

Materials and Methods: A prospective interventional non-randomized controlled study compared two groups (PRE and POST groups) of 20 spontaneously conscious ICU patients.

Results: Subjectively evaluated sleep quality was poor in the entire sample $(n=40)$ [Richards-Campbell Sleep Questionnaire (RCSQ) total 49.2 \pm 25.1$]$. The mean total sleep time was $389.0 \pm 78.8 \mathrm{~min}$, the Sleep Efficiency index (SEI) was $81.1 \pm 16.4 \%$, and the number of awakenings per night was $18.4 \pm 9.79$. The quality of sleep (both subjective and objective) was not significantly improved following the application of the sleep protocol (POST group), as inferred from most of the studied parameters. Subjective assessment yielded better results (RCSQ total: 45.1 PRE vs 51.1 POST); however, they were not statistically significant. Paradoxically, statistically significantly better results were observed for SEI (86.6\% PRE vs $75.9 \%$ POST, $p=0.044$ ), total sleep time (416 min PRE vs 364 min POST, $p=0.044)$, and noise $(T=2.11, p=0.046)$ in the control group.

Conclusion: Although the results failed to confirm that the multicomponent protocol exerted a significant effect, its implementation in clinical practice may be valuable. In a selected group of ICU patients, the proposed interventions may aid in achieving good sleep and in improving their overall comfort.
\end{abstract}

Keywords: Sleep, Actigraphy, Multicomponent sleep protocol, RichardsCampbell Sleep Questionnaire, Intensive care unit
Öz

Giriş: Yoğun bakım ünitesine (YBÜ) kabul edilen hastalarda uyku bozukluğu yaygındır ve çeşitli olumsuz etkilerle ilişkilidir. Bu çalışmada, çok bileşenli bir uyku protokolünün uygulanmasının hem sübjektif (bir anket ile değerlendirilen) hem de objektif olarak (aktigrafi kullanılarak ölçülen) uyku kalitesini iyileştirip iyileştirmediğinin araştırıması amaçlandı.

Gereç ve Yöntem: Ileri dönük girişimsel, randomize olmayan kontrollü bir çalışmada, 20 spontan bilinci açık YBÜ hastasından oluşan iki grup (PRE ve POST gruplar) karşılaştırıldı.

Bulgular: Subjektif olarak değerlendirilen uyku kalitesi tüm örneklemde zayıftı ( $n=40)$ [Richards-Campbell Uyku Anketi (RCSQ) toplam 49,2 $\pm 25,1]$. Ortalama toplam uyku süresi $389,0 \pm 78,8$ dk, Uyku Etkinlik indeksi (SEI) $\% 81,1 \pm 16,4$ ve gece uyanma sayısı $18,4 \pm 9,79$ idi. Uyku kalitesi (hem sübjektif hem de objektif), incelenen parametrelerin çoğundan anlaşıldığı gibi, uyku protokolünün (POST grubu) uygulanmasının ardından önemli ölçüde düzelmedi. Subjektif değerlendirme daha iyi sonuçlar verdi (RCSQ toplamı: PRE'de 45,1'ye karşılık POST'de 51,1); ancak istatistiksel olarak anlamlı değillerdi. Paradoksal olarak, kontrol grubunda SEl (PRE'de \%86,6'ya karşוlık POST'de \%75,9, $\mathrm{p}=0,044)$, toplam uyku süresi ( $P R E^{\prime} \mathrm{de} 416 \mathrm{dk}^{\prime}$ ya karşılık POST'de $364 \mathrm{dk}, \mathrm{p}=0,044)$ ve gürültü $(T=2,11, \mathrm{p}=0,046)$ için istatistiksel olarak anlamlı derecede daha iyi sonuçlar gözlendi.

Sonuç: Sonuçlar çok bileşenli protokolün önemli bir etki ortaya koymadığını doğrulamakta basarısız olsa da, klinik pratikte uygulanması değerli olabilir. Seçilmiş bir YBÜ hastası grubunda, önerilen müdahaleler iyi bir uykuya ulaşmaya ve genel konforlarını iyileştirmeye yardımcı olabilir.

Anahtar Kelimeler: Uyku, Aktigrafi, Çok bileşenli uyku protokolü, Richards-Campbell Uyku anketi, Yoğun bakım ünitesi

\footnotetext{
Address for Correspondence/Yazıșma Adresi: Hana Locihová MSN, PhD, AGEL Research and Training Institute, Prostějov, Department of Anaesthesiology and Resuscitation and Intensive Care Medicine,Hospital Valašské Meziř́č́í, and Secondary Nursing School AGEL, Ostrava, Czech Republic Phone: +90 0420739026151 E-mail: h.reichelova@seznam.cz ORCID-ID: orcid.org/0000-0002-4854-394X Received/Geliş Tarihi: 16.05.2020 Accepted/Kabul Tarihi: 06.07.2020 ${ }^{\circ}$ Copyright 2020 by Turkish Sleep Medicine Society / Journal of Turkish Sleep Medicine published by Galenos Publishing House.
} 


\section{Introduction}

The importance of sleep and sleep impairment in intensive care unit (ICU) patients is an increasingly discussed issue. This may be evidenced by the fact that the US-based Society of Critical Care Medicine updated and extended its 2013 globally accepted recommendations, entitled Clinical Practice Guidelines for the Management of Pain, Agitation, and Delirium in Adults Patients in the ICU, to include two new topics, namely immobility and sleep disruption (1). Impaired sleep is a frequent and significant stressor in ICU patients $(2,3)$. Multiple studies have confirmed that in intensive care patients, sleep architecture is impaired $(2,4)$, with as much as $57 \%$ of their sleep being during the day (5). Sleep disruption is associated with many adverse effects on the organism such as anxiety, a higher pain threshold, impaired immune function, a higher incidence of delirium or prolonged mechanical ventilation $(1,6,7)$. Recently, studies have also shown an association between sleep architecture, prolonged hospital stays and increased mortality $(8,9)$. The etiology of sleep disorders in ICU patients is multifactorial. Factors affecting sleep may be classified as (a) non-environmental (pain, other physical discomfort, underlying disease, stress, etc) and (b) environmental (noise, light, nursing interventions, etc) (10). Despite an increasing number studies demonstrating the benefit of complementary and alternative interventions in healthy individuals (11), studies evaluating the effect of these interventions in ICUs have yielded inconsistent results $(1,6)$. When assessing sleep in ICU patients, a major pitfall is the selection of a suitable assessment tool (12). According to recommendations (1), routine monitoring using polysomnography (PSG), actigraphy (ACT) or the bispectral index is not recommended; at the same time, however, an effort should be made to use validated self-assessment questionnaires and scales to evaluate sleep quality as this is often omitted (13). For its verified psychometric properties, the RichardsCampbell Sleep Questionnaire (RCSQ) is widely recommended $(14,15)$. Even though pharmacological interventions rapidly improving the quality of sleep are readily available, they may have numerous adverse effects (intolerance, withdrawal syndrome, hemodynamic instability) (16). Therefore, the trend is to develop a multimodal approach built on implementation of a multicomponent protocol for sleep care based on nonpharmacological procedures. These procedures are inexpensive and easy to apply and yet are rarely utilized $(17,18)$ with inconsistent results $(19,20)$ and little support from evidence $(1)$. The study aimed to investigate the effect of a multicomponent sleep protocol on the quality of sleep in ICU patients assessed both subjectively (with the RCSQ) and objectively (with ACT) and supplemented with a single noise measurement.

\section{Materials and Methods}

A single-center prospective interventional non-randomized non-controlled study.

The study sample comprised 40 patients (20 in the PRE Group and 20 in the POST Group) admitted to a general ICU of the Nový Jičín Hospital between September 2018 and January
2019 (12 beds, unselected admission of patients). The inclusion criteria were as follows: full consciousness (Glasgow Coma scale score 15; orientation to place, time and person), an ICU stay of more than 24 hours, age over 18 years and voluntary consent to participate in the research). The exclusion criteria were previous sleep disorder treatment, neurocognitive dysfunction (cognitive deficit/dementia, organic brain dysfunction), structural brain damage (trauma, stroke), ICU readmission for worsening of the condition, delirium of various etiologies or withdrawal syndrome, administration of sedatives in the previous 24 hours and patient refusal to participate.

Sleep quality and quantity was assessed (using the RCSQ and ACT) in two different patient groups and in two different time periods. The control group (PRE, $n=20$, September 2018-December 2018) consisted of patients with no specific sleep-promoting interventions and treated in accordance with local standards. In the intervention group (POST, n=20, MarchJune 2019), sleep quality was assessed following implementation of a multicomponent sleep protocol that took place in January and February 2019. Patient enrollment, ACT measurements and questionnaire data collection were performed by two trained nurses.

The questionnaires were filled in by patients helped by the nurse once during their hospital stay, after previous nighttime sleep monitoring (between 7 a.m. and 9 a.m.). On average, the questionnaires took 2-5 minutes to complete.

The actigraph wGT3X-BT (ActiGraph, USA) was placed on the non-dominant wrist. The epoch length was set at 60 seconds. The obtained data were processed using software (ActiLife 6.13.3, ActiGraph) and the Cole-Kripke algorithm (21). The monitoring was carried out from 9 p.m. to $5 \mathrm{a} . \mathrm{m}$. The analyzed ACT parameters are shown in Table 1.

Additionally, a single 12-hour noise measurement with a sound level meter (NI T8820, 4-in-1 Environment Meter, Netherlands) was performed during a night shift (6 p.m. to 6 a.m.). Nurses working the night shift were not informed about the noise measurement to eliminate bias (the Hawthorne effect) (22).

A protocol was developed according to Young et al. (23) and Elliott and McKinley (20). The algorithm included multicomponent measures aimed to identify and eliminate risk associated with sleep disruption (Figure 1). A detailed sleep history was divided into five components so that this need could be assessed in comprehensive manner (Table 2). Sleep-promoting strategies (Table 3 ) in the protocol comprised reduction of negative environmental stimuli (noise and light reduction, temperature optimization) and temporary solutions for inhibition of external stimuli (earplugs and eye masks). Concurrently there was an effort to apply sleep interventions of nursing procedures (education, clustering activities). The protocol algorithm was also supplemented with monitoring of pain and delirium and interventions to reduce them. During the break, the staff was educated on the importance of sleep and adverse effects of sleep disorders through training and posters permanently available in their wards. Two trained nurses received extra education on individual components of the sleep protocol and acted as mentors for the other nursing staff 
members. Patients in the POST Group were offered earplugs (E-A-R ${ }^{\text {TM }}$ UltraFit ${ }^{\text {TM}}$; 3M, Maplewood, Minnesota, USA) and eye masks (Daydream Basic Silk, China). Implementation of the sleep protocol applied to all nursing staff members.

The study complied with the Declaration of Helsinki and was approved by the Nový Jičín Hospital ethics committee (protocol no: INT2017007, date: 31.12.2019). Respondents participated voluntarily and their anonymity was ensured. Permission to translate the questionnaire into Czech was obtained directly from its author, Prof. K. C. Richards.

\begin{tabular}{|l|l|}
\hline Table 1. Definition of various actigraphy parameters \\
\hline Actigraphy parameter & Definition \\
\hline Time in bed (min) & $\begin{array}{l}\text { The time between the start and } \\
\text { the end of the recording }\end{array}$ \\
\hline Total sleep time (min) & $\begin{array}{l}\text { The total number of minutes } \\
\text { scored as "asleep" }\end{array}$ \\
\hline Sleep efficiency (\%) & $\begin{array}{l}\text { Number of sleep minutes divided } \\
\text { by the total number of minutes } \\
\text { the subject was in bed multiplied } \\
\text { by 100 }\end{array}$ \\
\hline Wake after sleep onset (min) & $\begin{array}{l}\text { The total number of minutes the } \\
\text { subject was awake after sleep } \\
\text { onset occurred. }\end{array}$ \\
\hline Number of awakenings (-) & Number of awakenings per night \\
\hline Average awakening length (min) & $\begin{array}{l}\text { The average length, in minutes, } \\
\text { of all awakening episodes }\end{array}$ \\
\hline Sleep Fragmentation index (-) & $\begin{array}{l}\text { Expressed as a percentage and } \\
\text { calculated as the sum of the } \\
\text { proportion of all epochs from } \\
\text { sleep onset } \\
\text { to sleep offset that were mobile* }\end{array}$ \\
\hline $\begin{array}{l}* \text { : Actigraph software programs used and was calculated per nighttime } \\
(21: 00 \text { to 05.00) }\end{array}$
\end{tabular}

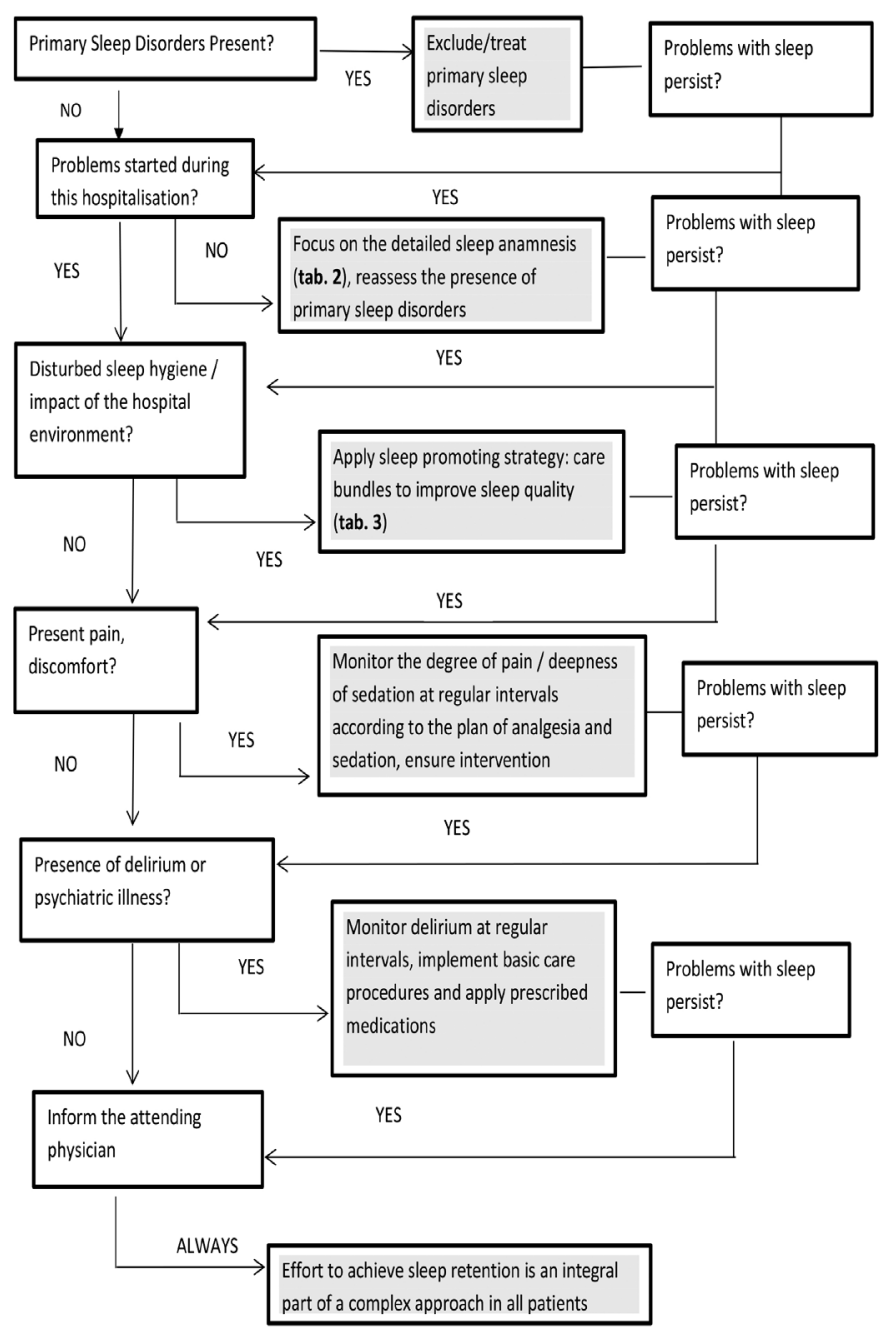

Figure 1. Multicomponent sleep protocol

\begin{tabular}{|l|l|}
\hline \multicolumn{2}{|l|}{ Table 2. Detailed sleep anamnesis } \\
\hline Domain of sleep & Examples of questions \\
\hline Sleeping hygiene & $\begin{array}{l}\text { Do you have difficulty falling asleep? Do you have an increased need for sleep during the day? } \\
\text { What does your sleep / being awake cycle look like? How many hours at night do you sleep unin- } \\
\text { terruptedly? How long does it take before you fall asleep? How many times do you wake up during } \\
\text { a (typical) night? How long will it take you to fall asleep then? Do you snore at night? Do you have } \\
\text { breathing pauses? Do you have to move your feet or have unpleasant feelings in them before you } \\
\text { fall asleep? Do you move your legs even in your sleep? }\end{array}$ \\
\hline Behavioural and environmental factors & $\begin{array}{l}\text { When did your problems begin? Is it bound to a change of the environment (hospital)? What are } \\
\text { the differences in sleep hygiene at home and in the hospital? Is the level of noise and lighting a } \\
\text { trigger factor of your sleep disorders? Do you always wake up when your nurse carries out any } \\
\text { intervention? }\end{array}$ \\
\hline Patient comfort & $\begin{array}{l}\text { Is there any intervention to help you sleep? Is your pain adequately assessed and treated? Do you } \\
\text { have other troubles that prevent you from sleeping? }\end{array}$ \\
\hline Sleeping agents & $\begin{array}{l}\text { Do you regularly take any medication to induce sleep? Do you use alternative methods to induce } \\
\text { sleep? (balm, thermophore). Are you used to having alcohol/cigarette in the evening to induce } \\
\text { sleep? }\end{array}$ \\
\hline Psychosocial factors & $\begin{array}{l}\text { Has your mood changed since you were admitted to hospital? Do you have any previous negative } \\
\text { experience with your hospital stay? Do you suffer from distress from the hospital stay (confrontation } \\
\text { with the impacts of illness)? }\end{array}$ \\
\hline
\end{tabular}




\begin{tabular}{|c|c|c|}
\hline Region & Sleep barrier & Examples of nursing interventions to optimise sleep \\
\hline Environment optimisation & $\begin{array}{l}\text { Noise } \\
\text { Light } \\
\text { Temperature }\end{array}$ & $\begin{array}{l}\text { - offer earplugs } \\
\text { - expand the range of alarms } \\
\text { - behavioural activities to reduce staff noise } \\
\text { - education of visits regarding behaviour and observance of principles at the department } \\
\text { - close the door (if possible) } \\
\text { - cleaning only from } 6.00 \text { - } 18.00 \\
\text { - offer an eye mask } \\
\text { - turn down/turn off light at } 22.00 \\
\text { - ensure the optimum room temperature }\end{array}$ \\
\hline Sleep interventions & $\begin{array}{l}\text { Disturbed sleep } \\
\text { hygiene }\end{array}$ & $\begin{array}{l}\text { - education on regime measures (restrain of caffeine and cigarettes and other stimu- } \\
\text { lants at bedtime, not to create a working environment in bed, not to overeat before } \\
\text { going to bed) } \\
\text { - restriction of daily sleep (short rest period allowed in the afternoon) } \\
\text { - reduce sleep disturbing medications } \\
\text { - clustering night care activities } \\
\text { - ban on routine bathing of patients at night ( } 22.00-6.00 \text { ) } \\
\text { - critically assess the importance of nighttime collections and the scope of monitoring } \\
\text { - set the appropriate ventilation mode } \\
\text { - cognitive activation during the day } \\
\text { - regular pain assessment and ensuring good analgesia } \\
\text { - regular assessment of delirium and its development } \\
\text { - positioning (use of pillows, positioning aids) } \\
\text { - early mobilisation of the patient on bed (involvement of physiotherapists in care: } \\
\text { early mobility protocol) }\end{array}$ \\
\hline
\end{tabular}

\section{Statistical Analysis}

The changes of noise level between 6 p.m. and 6 a.m. for untreated (empty circles) and treated (full circles) patients were evaluated by polynomic dependence of the $2^{\text {nd }}$ degree including the treatment effect. The dependent variable was transformed by a box-cox transformation to attain a symmetric distribution and homoscedasticity in residuals. The optimum degree of polynomial, data homogeneity and data symmetry in the transformed data were tested as described elsewhere $(24,25)$. The between-group differences were evaluated by unpaired t-test for equal group variance for continuous variables with Gaussian distribution and constant variance. The remaining continuous variables were evaluated using a robust unpaired Mann-Whitney test. The between-group differences for dichotomous variables were tested by a Fisher's Exact test. Statistical software Statgraphics Centurion v. 18.1.06 (Statgraphics Technologies, Inc., The Plains, Maryland, USA) was used for the data evaluation.

\section{Results}

The sample comprised a total of 40 patients, of which 20 were in the PRE Group and 20 in the POST Group. Both sexes were equally represented, with 11 females and 9 males in both groups. (Dependence of sex on the effect from interventions in the two groups, PRE and POST, was determined by Fisher's
Exact test which showed no significant difference.) The mean age of the participants was $65.9 \pm 14.5$ years, $65.7 \pm 14.8$ years in the PRE Group and 66.2 \pm 14.1 years in the POST Group. The mean body weight was $81.0 \pm 16.2 \mathrm{~kg}$ for the entire sample, $80.4 \pm 17.1$ and $80.6 \pm 16.0 \mathrm{~kg}$, respectively. With a mean BMI of $28.7 \pm 5.25$, overweight was typical for the entire sample. The mean BMI was higher in the PRE Group (29.2 \pm 6.18$)$ than in the POST Group (27.9 \pm 4.24$)$. Statistical tests were performed to assess the dependence of selected variables (age, body weight BMI) in the groups. None of the variables was shown to be statistically significant in the groups: age $(p=0.865)$, body weight $(p=0.759), B M I(p=0.715)$.

In the entire sample, the mean RCSQ total was $49.2 \pm 25.1$ and the calculated Sleep Efficiency index (SEI) was 66.1 \pm 9.8 . This suggests a relatively poor quality of sleep of the participants. The best rated questionnaire item was returning to sleep (54.2 \pm 30.8$)$. In contrast, the lowest rated item was sleep latency (43.1 \pm 30.6$)$. The other items were rated as follows (in descending order): subjectively perceived sleep quality (52.0 \pm 31.6$)$, awakenings $(49.7 \pm 27.6)$ and sleep depth (47.2 \pm 25.8$)$. The subjectively perceived noise level, an optional item, was assessed separately $(60.1 \pm 27.7)$. Relevant statistical tests were performed to study differences in the effects of the interventions on subjectively perceived quality of sleep between the groups (PRE vs POST). The subjectively perceived noise 
level was the only item for which the POST Group showed statistically significantly better results: $52.3 \pm 25.6$ (PRE) vs $65.6 \pm 29.3$ (POST) $(p=0.047)$. This was supported by results of measurements with a sound level meter and estimation of the dependence of sound levels on time in both groups (PRE vs POST) by regression analysis. The noise profile followed a U-shaped curve, with different minimum values between midnight and 1 a.m. and identical maximum values of $64 \mathrm{~dB}$. Noise was found to be strongly dependent on time $\left(r^{2}=64.7 \%\right.$, $p<0.001)$; there was a consistent borderline shift towards higher values in the POST Group ( $T=2.11, \mathrm{p}=0.046)$ (Figure 2).

When differences in individual items between the groups (PRE vs POST) were analyzed, two items were rated worse (not statistically significantly) in the POST Group, namely sleep depth (PRE 48.6 \pm 24.7 vs POST 46.0 $\pm 26.9, p=0.720$ ) and sleep latency (PRE 44.4 \pm 32.0 vs POST 41.7 $\pm 29.1, p=0.842$ ). The remaining three items were rated better (not statistically significantly) in the POST group: awakenings (PRE $47.1 \pm 27.2$ vs. POST 52.2 $\pm 27.7, p=0.564$ ), returning to sleep (PRE 47.8 \pm 27.9 vs POST 61.0 $\pm 32.1, \mathrm{p}=0.217$ ) and sleep quality (PRE 50.2 \pm 30.2 vs POST 54.7 $\pm 33.0, p=0.782$ ). Both the RCSQ total and the calculated SEI were higher in the POST Group, once again without statistical significance: PRE (RCSQ total) $47.6 \pm 25.0$ vs. POST 51.1 $\pm 25.2(p=0.693)$ and PRE (SEI) $65.4 \pm 9.76$ vs POST $66.8 \pm 9.82(p=0.686)$ (results summarized in Table 4).

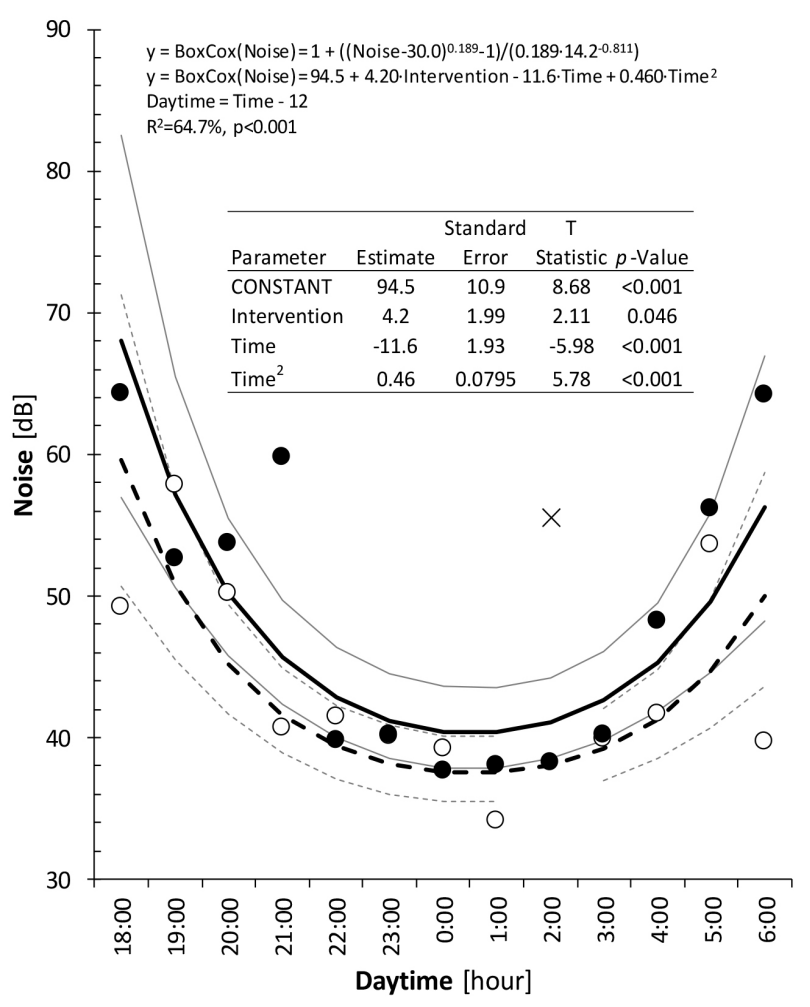

Figure 2. Changes of noise level between 6 p.m. and 6 a.m. for untreated (empty circles) and treated (full circles) patients as fitted by polynomic dependence of the $2^{\text {nd }}$ degree including the treatment effect
In the entire sample, sleep efficiency (SE) assessed by ACT reached $81.1 \pm 16.4 \%$, also suggesting poor sleep quality (the cut-off is $85 \%$ ). For all cases, the time in bed was identical (8 hours, from 9 p.m. to 5 a.m.) and the mean total sleep time (TST) was $389.0 \pm 78.8 \mathrm{~min}$. The mean wake after sleep onset (WASO) was $90.4 \pm 78.4 \mathrm{~min}$ and the number of awakenings per night was $18.4 \pm 9.79$, with a mean duration of $4.65 \pm 2.89 \mathrm{~min}$. The sleep fragmentation index (SFI) reached $44.9 \pm 20.6$. When comparing ACT parameters between the groups (PRE vs POST), the POST group showed poorer sleep quality as evidenced by all parameters, with three being statistically significant. The POST Group subjects had lower (SE PRE $86.6 \pm 9.39$ vs. SE POST $75.9 \pm 19.6, p=0.044$ ), shorter (TST PRE $416.0 \pm 45.1$ vs. TST POST $364.0 \pm 94.0 \mathrm{~min}, \mathrm{p}=0.044)$ and longer duration of awakenings (PRE $3.56 \pm 1.3$ vs POST $5.69 \pm 3.52 \mathrm{~min}, \mathrm{p}=0.016$ ). In the case of WASO, the statistical significance was borderline (PRE $64.5 \pm 45.1$ vs POST $115.0 \pm 93.5(p=0.066)$. Although the two remaining parameters did not reach statistical significance, they were also worse in the POST Group: the number of awakenings (PRE 17.1 \pm 8.77 vs POST 19.6 $\pm 10.5 \mathrm{~min}, \mathrm{p}=0.485$ ) and SFI (PRE 40.4 \pm 16.2 vs POST 49.9 $\pm 23.2, p=0.140$ ). Additionally, the comfort of the two selected interventions (earplugs and eye masks) was assessed using the Comfort Scale in the POST Group. The subjects rated their subjective feelings on a scale from 1 (very comfortable) to 5 (very uncomfortable). Both aids showed good results (2.800 \pm 0.894 for earplugs and $2.75 \pm 1.02$ for eye masks) (Table 4).

\section{Discussion}

Implementation of standards and protocols is part of efforts to improve the quality of care provided in ICUs. Nursing procedures, including sleep quality interventions, are no exception. However, these sleep-improving interventions are seldom used, as seen from two multinational studies. In a US-based international study (24 countries, 1223 critical care providers), only $32 \%$ of respondents reported implementation of a sleep protocol (18). Even lower implementation rates were found in a recent Dutch study (10 countries, 522 ICUs), with sleep protocols being used in only $9 \%$ of ICUs and sleep being routinely assessed (with questionnaires) in only 1\% of ICUs (17). A major pitfall is difficult interpretation of obtained data due to considerable bias and confounding. The factors to be considered include, among others, the number of nights assessed, considerable variations in the design of available studies, sample size, underlying disease, types of interventions assessed, assessment methods themselves and record length $(1,19)$. Heterogeneity of obtained data results in poor quality evidence and possibly explains the weak adoption of the investigated interventions by experts and their subsequent implementation in clinical practice. The present study results may be interpreted with regard to the methods used, that is, the RCSQ vs. noise meter vs ACT. Following protocol implementation, subjectively assessed sleep quality was slightly better, albeit insignificantly. We found five studies assessing the effect of original multicomponent sleep protocols. Of those, two US studies $(26,27)$ also failed to found a significant 


\begin{tabular}{|c|c|c|c|c|c|c|c|c|c|c|c|c|c|c|c|c|c|c|c|c|c|c|c|c|}
\hline & & & & 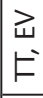 & $\begin{array}{l}\stackrel{3}{\prime} \\
F\end{array}$ & 离 & 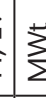 & 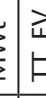 & & & $\begin{array}{l}\vec{u} \\
\mathbb{F} \\
\end{array}$ & $\begin{array}{l}3 \\
\text { 出 }\end{array}$ & & $\begin{array}{l}己 \\
\text { E } \\
\text { E }\end{array}$ & \begin{tabular}{|l} 
\\
H \\
\end{tabular} & $\sum$ & $\begin{array}{l}\vec{Z} \\
\text { E }\end{array}$ & 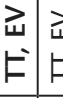 & 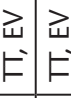 & $\begin{array}{l}\vec{z} \\
= \\
=\end{array}$ & $\sum_{\Sigma}^{n}$ & & 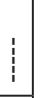 & \\
\hline & & 2 & & $\begin{array}{l}n \\
0 \\
\infty \\
0 \\
0\end{array}$ & $\begin{array}{l}\text { oे } \\
\text { ò }\end{array}$ & 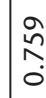 & 年 & 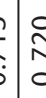 & & $\begin{array}{c}\tilde{y} \\
\vdots \\
0 \\
0\end{array}$ & $\begin{array}{l}\text { 苟 } \\
\text { ?n: } \\
0\end{array}$ & 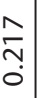 & 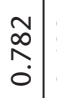 & $\begin{array}{l}n \\
\hat{o} \\
0 \\
0\end{array}$ & $\begin{array}{l}0 \\
0 \\
0 \\
0 \\
0\end{array}$ & $\begin{array}{l}\hat{f} \\
\dot{0} \\
0\end{array}$ & $\begin{array}{l} \pm \\
⿱ \\
0 \\
\dot{0}\end{array}$ & 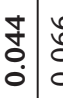 & \begin{tabular}{l|l}
0 & \multicolumn{1}{c}{} \\
$\vdots$ & 0 \\
$\vdots$ & 0 \\
0 & 0 \\
\end{tabular} & $\begin{array}{lll}0 \\
0 \\
0 \\
0\end{array}$ & \begin{tabular}{l}
0 \\
\multirow{1}{0}{} \\
$\dot{0}$
\end{tabular} & & 1 & 䘚 \\
\hline & & 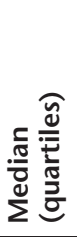 & & 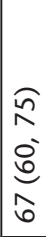 & 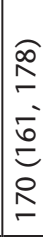 & $\begin{array}{l}\text { నू } \\
\infty \\
0 \\
0 \\
\infty\end{array}$ & 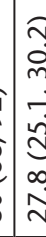 & 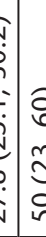 & & 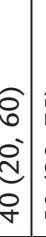 & $\begin{array}{l}\hat{n} \\
0 \\
0 \\
0 \\
0 \\
n\end{array}$ & 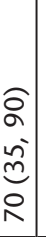 & $\begin{array}{l}\widehat{\partial} \\
\infty \\
\circ \\
\tilde{n} \\
0 \\
i\end{array}$ & 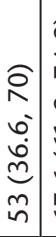 & 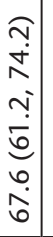 & $\begin{array}{l} \\
\widehat{\alpha} \\
0 \\
0 \\
0 \\
\vdots \\
\infty\end{array}$ & $\begin{array}{c}\tilde{n} \\
\stackrel{0}{0} \\
0 \\
m \\
0 \\
0 \\
0 \\
\infty \\
\infty\end{array}$ & 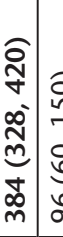 & 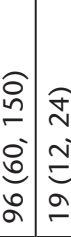 & 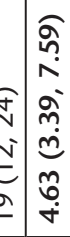 & 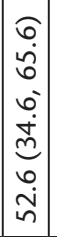 & 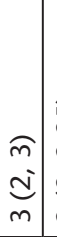 & 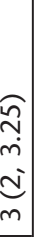 & 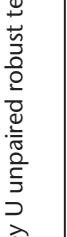 \\
\hline & & 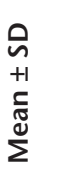 & & 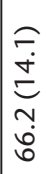 & 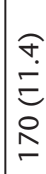 & $\begin{array}{l}0 \\
0 \\
0 \\
0 \\
0\end{array}$ & 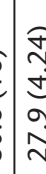 & 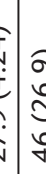 & 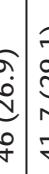 & 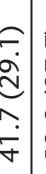 & 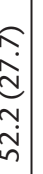 & $\begin{array}{l}\widehat{c} \\
\stackrel{\vec{v}}{\tilde{c}} \\
\bar{\sigma}\end{array}$ & 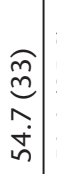 & 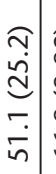 & $\left|\begin{array}{c}\widehat{O} \\
0 \\
\vdots \\
\infty \\
0 \\
\dot{0} \\
0\end{array}\right|$ & 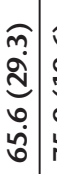 & 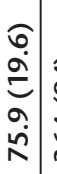 & 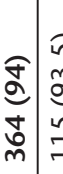 & 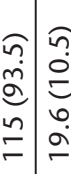 & 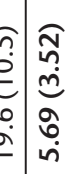 & 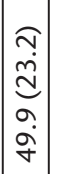 & $\begin{array}{c}\widehat{\sigma} \\
\infty \\
\infty \\
\stackrel{0}{0} \\
\infty \\
\dot{N}\end{array}$ & 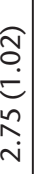 & \\
\hline & 气. & $\varepsilon$ & $\mp$ & $\bar{v}$ & $\bar{N}$ & $\bar{\sim}$ & $i \bar{\pi}$ & 5 & $\bar{v} \mid \overline{7}$ & $\bar{v}$ & $\overline{\mathbf{v}}$ & $\bar{\sim}$ & $\bar{v}$ & $\bar{v}$ & $\bar{v}$ & $\bar{N}$ & $\bar{N}$ & $\bar{N} \overline{7}$ & $\bar{v} \bar{N}$ & $\bar{v} \mid \bar{N}$ & $\bar{\sim}$ & ㄴ. & ㅇ. & \\
\hline & & 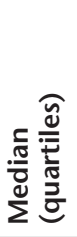 & & 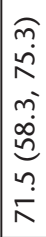 & 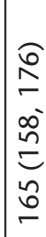 & 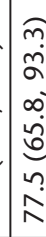 & $\begin{array}{c}0 \\
0 \\
0 \\
0 \\
\vdots \\
z \\
2 \\
\lambda\end{array}$ & 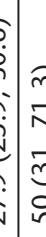 & 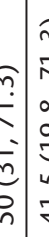 & 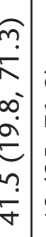 & 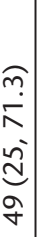 & 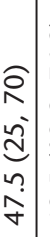 & 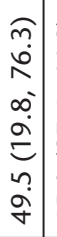 & 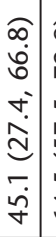 & 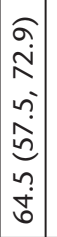 & 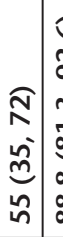 & 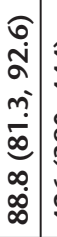 & 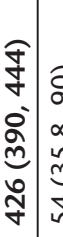 & 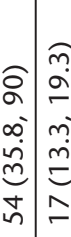 & 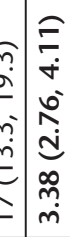 & 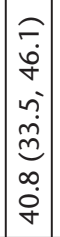 & & & \\
\hline & & 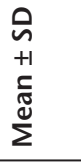 & & $\begin{array}{l}\hat{\infty} \\
\stackrel{+}{ \pm} \\
\end{array}$ & 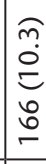 & 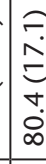 & $\begin{array}{l}\infty \\
\frac{1}{8} \\
2 \\
2\end{array}$ & 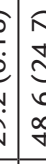 & 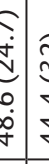 & 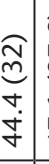 & 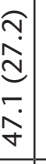 & 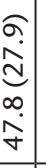 & 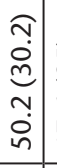 & $\begin{array}{l}\widetilde{a} \\
\mathfrak{d} \\
\underline{d} \\
\dot{f}\end{array}$ & $\left|\begin{array}{c}0 \\
0 \\
\vdots \\
0 \\
0 \\
\vdots \\
b\end{array}\right|$ & 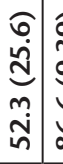 & $\begin{array}{c}\hat{\sigma} \\
\hat{m} \\
\vdots \\
0 \\
\dot{\infty} \\
\infty\end{array}$ & 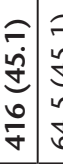 & 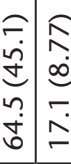 & 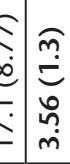 & 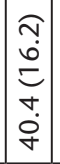 & & & \\
\hline & 岕 & $=$ & $a$ & న & ㄱ & ৯ & ก & ৩ & $\begin{array}{l}\vec{v} \\
\end{array}$ & సి & จे & จ & $\stackrel{\sim}{ }$ & ㄴ. & i & ๙ & จ & ๙ิ) & ঃ & 2) & ㄱ. & & & \\
\hline 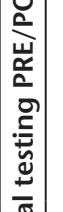 & & 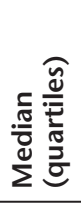 & & 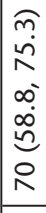 & 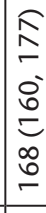 & 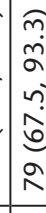 & 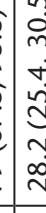 & 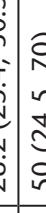 & 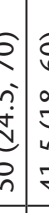 & $\begin{array}{l}\delta \\
\delta \\
\infty \\
\infty \\
\vdots \\
n \\
\dot{\sigma}\end{array}$ & 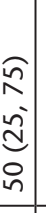 & 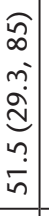 & 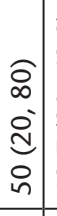 & $\begin{array}{l}\widehat{m} \\
0 \\
0 \\
0 \\
0 \\
\hat{\sigma} \\
\dot{\sigma}\end{array}$ & $\left|\begin{array}{c}0 \\
n \\
n \\
0 \\
0 \\
0 \\
0 \\
n \\
m \\
\dot{b} \\
0\end{array}\right|$ & 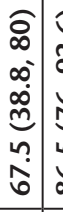 & 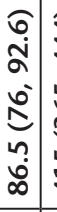 & 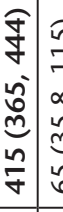 & 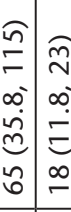 & 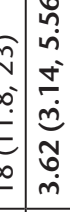 & $\mid \begin{array}{c}\hat{\sigma} \\
\hat{n} \\
\tilde{n} \\
\tilde{n} \\
\tilde{n} \\
m \\
\dot{j} \\
\dot{f}\end{array}$ & & & \\
\hline 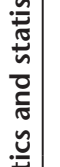 & & $\begin{array}{l}0 \\
+1 \\
+1 \\
\frac{0}{0} \\
\sum \\
\sum\end{array}$ & & 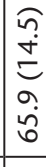 & $\begin{array}{l}\widetilde{\sigma} \\
\infty \\
\infty \\
0\end{array}$ & 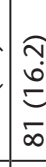 & 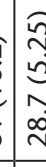 & 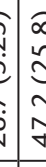 & 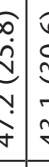 & 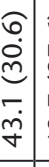 & 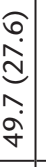 & 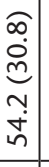 & $\begin{array}{l}0 \\
\vdots \\
\dot{m} \\
\sim \\
n\end{array}$ & 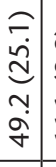 & 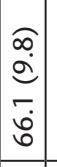 & 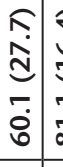 & 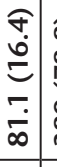 & 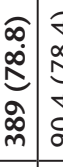 & 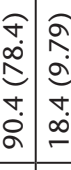 & 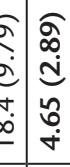 & 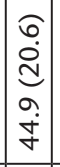 & & & 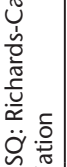 \\
\hline & $\bar{\gtrless}$ & $=$ & $V_{V}$ & q & q & f & q & $f$ & q & of & q & q & 아 & 이 & 우 & q & q & $q$ & 암아 & o & 아 & 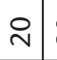 & ৯ & \\
\hline 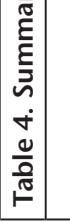 & & $\frac{\frac{0}{0}}{\frac{0}{\circ}}$ & & & $\stackrel{\oplus}{I}$ & $3^{\infty}$ & $\sum_{m}$ & $\overline{\bar{z}}$ & 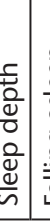 & 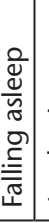 & 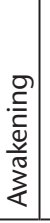 & 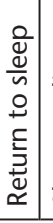 & $\begin{array}{l}\frac{3}{0} \\
\frac{3}{0} \\
\overline{0} \\
\frac{0}{0} \\
\frac{\mathbb{Q}}{n}\end{array}$ & 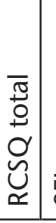 & $\bar{\sim}$ & 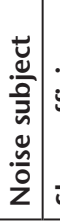 & 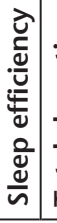 & 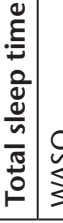 & 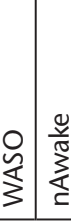 & 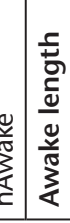 & 咅 & $\begin{array}{l}\tilde{o} \\
\frac{\tilde{\Xi}}{2} \\
\frac{2}{\bar{w}}\end{array}$ & 总 & 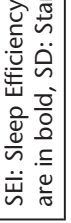 \\
\hline
\end{tabular}

effect. In contrast, there was a statistically significant positive effect in three studies (28-30). Similarly, the present study failed to show a positive effect of interventions even with objectively measurable parameters (noise meter, ACT). Despite the staff's increased awareness, noise levels were significantly higher in the POST Group $(p<0.001)$. The most likely explanation is the fact that extended clinical knowledge do not lead to changes in the staff's behavior. Interventions aimed at environment optimization, with an emphasis on noise reduction, are most widespread and their effect is most studied (31). The role of noise and other environmental factors with regard to sleep disorders have been widely discussed but the outcomes are inconsistent. We found three experimental studies (32-34) and one observational study (35) showing an association between exposure to noise and changes in sleep architecture as measured by PSG. These findings were refuted by three studies (36-38) stating that environmental factors are overestimated with regard to sleep disorders. Also, a recent Danish study (36) did not confirm the association between noise levels and sleep quality measured by PSG $(p=0.3)$. In a study by Gabor et al. (38), $10 \mathrm{~dB}$ sound elevations occurred $36.5 \pm 20.1$ times an hour, causing $20.9 \pm 11.3 \%$ of total awakenings. For the remaining awakenings (68.1 $\pm 9.7 \%)$, the causes were not identified. Similar results were found in an American descriptive study (37) stating that noise was partly responsible for altered sleep architecture but was not the main cause of sleep fragmentation $(11.5 \pm 11.8 \%$ of arousals and $17.0 \%$ of awakenings). The present study also showed a strong association between time and noise levels, with minimum values between midnight and 1 a.m. Noise levels consistently exceeded the recommended standards, with the highest level being $64.3 \mathrm{~dB}$. According to the US Environmental Protection Agency, daytime and nighttime noise levels in healthcare facilities should not exceed $45 \mathrm{~dB}$ and $35 \mathrm{~dB}$, 
respectively. Our measurements are consistent with those by Darbyshire and Young (39) who compared noise levels suggested by the WHO with actual noise levels in ICUs and found these to be high above the recommended standards. In an effort to ensure a good sleep, our patients were offered earplugs and eye masks. Both interventions were considered comfortable. A meta-analysis by Litton et al. (40) included six studies $(n=681)$ assessing compliance with the method and found a mean per-patient noncompliance of $13.1 \%$. The study also confirmed that earplug placement was associated with reduced delirium ( $\mathrm{RR} 0.59,95 \% \mathrm{Cl}, 0.44-0.78$ ) which is a potentially important conclusion. In the present study, ACT measurements confirmed expected sleep disruption in ICU patients. Similar results were shown in a systematic review by American authors (41) concerned with the use of ACT in ICUs (13 studies, 277 patients). The mean TST was 4.47.8 hours, SEl was $61-75 \%$ and number of awakenings 1.449.0 per night. In the present study, statistically significantly worse ACT results for the POST Group suggest that sleep interventions may not have a beneficial effect on objective sleep quality. This is also evidenced by a French study (42) that failed to confirm objective changes to sleep quality and quantity as measured by ACT even though patients reported subjective improvement following interventions. Frequent studies on ACT (compared to those on PSG) prove that the technique receives increasing attention. While in 1991, the proportion of studies (ACT:PSG) was $1: 10$, it rose to $1: 4$ in 2009. The position of ACT monitoring and interpretation of its results in clinical practice remains quite unclear (43). In the ICU setting, ACT measurements are negatively influenced by numerous factors. A considerable limitation is the absence of algorithms for assessing the population of ICU patients in whom ACT signals may not accurately correspond with the motor activity itself and thus the level of wakefulness (44). In ICU patients, reduced motor activity is common and conditioned by multiple factors: acute critical illness, pain, administration of analgesics or sedatives, etc. This pitfall of using ACT in ICUs has been confirmed by validation studies (45-47) showing that ACT is much less accurate than other methods (PSG, EEG) and tends to overstate the results (sleep quality and quantity). Another controversial point is placement of the ACT device. An American study (48) comparing measurement data (ankle vs. wrist) showed poor agreement between measurements and recommended that the two placement sites were not used interchangeably. However, this was refuted by another US study (49) showing a favorable correlation $(r=0.69, p<0.001)$. In an effort to use a uniform approach, most authors use the non-dominant wrist for ACT monitoring. Yet another important pitfall is the length of ACT records (daily vs nocturnal). Once again, there is considerable heterogeneity between studies. Some authors, namely those investigating primarily sleep quality, limited their study to nighttime only $(46,50,51)$. Other authors recorded longer periods of time and sleep assessment was a secondary outcome of their studies $(48,49,52)$. The clear benefits of ACT are availability, feasibility and minimal burden to patients. Its accuracy, however, remains debatable. There is a consensus $(6,41)$ that the method may be used in conscious ICU patients (a minority of the ICU population) as an additional tool for sleep quality assessment combined with another approach (questionnaires) or as a supportive tool for evaluating sleep-promoting strategies. Currently, the method is not recommended for routine sleep assessment in the ICU setting (1). At the same time, there are other possible uses of ACT in ICU patients: evaluating depth of sedation based on motor activity, diagnosing and quantifying ICU-acquired weakness (41) or objective assessment of post-ICU sleep disturbance $(53,54)$.

\section{Study Limitations}

The first limitation of the study is its design (single-center setting, small patient sample). Another limitation considerably reducing the applicability of results to the usual population of critically ill patients is that the subjects were conscious (most ICU patients are sedated or with structural damage). The third, absolutely essential, limitation is the short ACT record. For valid and comprehensive assessment of sleep quality, a high-quality multicenter randomized study is needed.

\section{Recommendations for practice}

- There is evidence that sleep is disrupted in ICU patients.

- Promoting sleep (and its quality) should be an integral part of comprehensive care for ICU patients.

- A multicomponent sleep protocol may have a positive effect on subjectively perceived sleep quality; there is no evidence that it positively influences objectively measured sleep quality.

- Assessment of the quality of sleep and effectiveness of the investigated sleep-promoting interventions in ICU patients is difficult and has many limitations.

\section{Conclusion}

The study failed to confirm that implementation of a multicomponent sleep protocol improves both subjective and objective sleep quality. Although some of the investigated parameters assessing sleep quality were slightly improved (without statistical significance), sleep-promoting interventions resulted in worse results for the objectively measured parameters. Despite the inconsistent outcomes, there are assumptions and signals that the sleep care protocol may be beneficial for ICU patients. To confirm this hypothesis, more research is needed.

\section{Ethics}

Ethics Committee Approval: The study complied with the Declaration of Helsinki and was approved by the Nový Jičín Hospital ethics committee (protocol no: INT2017007, date: 31.12.2019).

Informed Consent: Participants voluntarily participated and were kept anonymous.

Peer-review: Internally peer-reviewed.

\section{Authorship Contributions}

Concept: H.L., Design: H.L., Data Collection or Processing: K.Z., D.S., Analysis or Interpretation: H.L., K.A., Literature Search: H.L., K.Z., Writing: H.L., K.Z., K.A., D.S. 
Conflict of Interest: The authors are not aware of any conflict of interest.

Financial Support: The study was supported by AGEL internal grant project no. INT 2017007.

\section{References}

1. Devlin JW, Skrobik Y, Gélinas C, Needham DM, Slooter AJC, Pandharipande PP, Watson PL, Weinhouse GL, Nunnally ME, Rochwerg B, Balas MC, van den Boogaard M, Bosma KJ, Brummel NE, Chanques G, Denehy L, Drouot X, Fraser GL, Harris JE, Joffe AM, Kho ME, Kress JP, Lanphere JA, McKinley S, Neufeld KJ, Pisani MA, Payen JF, Pun BT, Puntillo KA, Riker RR, Robinson BRH, Shehabi $Y$, Szumita PM, Winkelman C, Centofanti JE, Price C, Nikayin S, Misak C), Flood PD, Kiedrowski K, Alhazzani W. Clinical Practice Guidelines for the Prevention and Management of Pain, Agitation/Sedation, Delirium, Immobility, and Sleep Disruption in Adult Patients in the ICU. Crit Care Med 2018;46:825-73.

2. Parthasarathy $S$, Tobin MJ. Sleep in the intensive care unit. Intensive Care Med 2004;30:197-206.

3. Rotondi AJ, Chelluri L, Sirio C, Mendelsohn A, Schulz R, Belle S, Im K, Donahoe M, Pinsky MR. Patients' recollections of stressful experiences while receiving prolonged mechanical ventilation in an intensive care unit. Crit Care Med 2002;30:746-52.

4. Cooper AB, Thornley KS, Young GB, Slutsky AS, Stewart TE, Hanly PJ. Sleep in critically ill patients requiring mechanical ventilation. Chest 2000;117:809-18.

5. Córdoba-Izquierdo A, Drouot X, Thille AW, Galia F, Roche-Campo F, Schortgen F, Prats-Soro E, Brochard L. Sleep in hypercapnic critical care patients under noninvasive ventilation: conventional versus dedicated ventilators. Crit Care Med 2013;41:60-8.

6. Flannery AH, Oyler DR, Weinhouse GL. The impact of interventions to improve sleep on delirium in the ICU: a systematic review and research framework. Crit Care Med 2016;44:2231-40.

7. Roche-Campo F, Thille AW, Drouot X, Galia F, Margarit L, CórdobaIzquierdo A, Mancebo J, d'Ortho MP, Brochard L. Comparison of sleep quality with mechanical versus spontaneous ventilation during weaning of critically ill tracheostomized patients. Crit Care Med 2013;41:1637-44.

8. Knauert MP, Gilmore EJ, Murphy TE, Yaggi HK, Van Ness PH, Han L, Hirsch LJ, Pisani MA. Association between death and loss of stage N2 sleep features among critically ill patients with delirium. J Crit Care 2018;48:124-9.

9. Boyko Y, Toft P, Ørding H, Lauridsen JT, Nikolic M, Jennum P. Atypical sleep in critically ill patients on mechanical ventilation is associated with increased mortality. Sleep Breath 2019;23:379-88.

10. Tembo AC, Parker V. Factors that impact on sleep in intensive care patients. Intensive Crit Care Nurs 2009;25:314-22.

11. Neuendorf R, Wahbeh H, Chamine I, Yu J, Hutchison K, Oken BS. The effects of mind-body interventions on sleep quality: a systematic review. Evid Based Complement Alternat Med 2015;2015:902708.

12. Hoey LM, Fulbrook P, Douglas JA. Sleep assessment of hospitalised patients: a literature review. Int J Nurs Stud 2014;51:1281-8.

13. Ye L, Keane K, Hutton Johnson S, Dykes PC. How do clinicians assess, communicate about and manage patient sleep in the hospital? J Nurs Adm 2013;43:342-7.

14. Richards KC, O'Sullivan PS, Philips RL. Measurement of sleep in critically ill patients. J Nurs Meas 2000;8:131-44.

15. Jeffs EL, Darbyshire JL. Measuring sleep in the intensive care unit: a critical appraisal of the use of subjective methods. J Intensive Care Med 2019;34:751-60.

16. Bourne RS, Mills GH. Sleep disruption in critically ill patients pharmacological considerations. Anaesthesia 2004;59:374-84.
17. Hofhuis JGM, Rose L, Blackwood B, Akerman E, McGaughey J, Egerod I, Fossum M, Foss $H$, Georgiou E, Graff HJ, Kalafati M, Sperlinga R, Berardo A, Schäfer A, Wojnicka AG, Spronk PE. Clinical practices to promote sleep in the ICU: a multinational survey. Int J Nurs Stud 2018;81:107-14.

18. Kamdar BB, Knauert MP, Jones SF, Parsons EC, Parthasarathy S, Pisani MA; Sleep in the ICU (SLEEPii) Task Force. Perceptions and practices regarding sleep in the intensive care unit. A survey of 1,223 critical care providers. Ann Am Thorac Soc 2016;13:1370-7.

19. Hu RF, Jiang $X Y$, Chen J, Zeng $Z$, Chen $X Y$, Li Y, Huining $X$, Evans D]. Non-pharmacological interventions for sleep promotion in the intensive care unit (Review). Cochrane Database Syst Rev 2015;2015:CD008808.

20. Elliott RM, McKinley S. The development of a clinical practice guideline to improve sleep in intensive care patients: a solution focused approach. Intensive Crit Care Nurs 2014;30:246-56.

21. Cole RJ, Kripke DF, Gruen W, Mullanney DJ, Gillin JC. Automatic Sleep / Wake Identification From Wrist Activity. Sleep 1992;15:461-9.

22. Wickström G, Bendix T. The "Hawthorne effect"-- what did the original Hawthorne studies actually show? Scand J Work Environ Health 2000;26:363-7.

23. Young JS, Bourgeois JA, Hilty DM, Hardin KA. Sleep in hospitalized medical patients, part 2: behavioral and pharmacological management of sleep disturbances. J Hosp Med 2009;4:50-9.

24. Meloun M, Militký J, Hill M, Brereton RG. Crucial problems in regression modelling and their solutions. Analyst 2002;127:433-50.

25. Meloun M, Hill M, Militký J, Vrbíková J, Stanická S, Škrha J. New methodology of influential point detection in regression model building for the prediction of metabolic clearance rate of glucose. Clin Chem Lab Med 2004;42:311-22 .

26. Kamdar BB, King LM, Collop NA, Sakamuri S, Colantuoni E, Neufeld KJ, Bienvenu OJ, Rowden AM, Touradji P, Brower RG, Needham $\mathrm{DM}$. The effect of a quality improvement intervention on perceived sleep quality and cognition in a medical ICU. Crit Care Med 2013;41:800-9.

27. Faraklas I, Holt B, Tran S, Lin H, Saffle J, Cochran A. Impact of a nursing-driven sleep hygiene protocol on sleep quality. J Burn Care Res 2013;34:249-54.

28. Patel J, Baldwin J, Bunting P, Laha S. The effect of a multicomponent multidisciplinary bundle of interventions on sleep and delirium in medical and surgical intensive care patients. Anaesthesia 2014;69:540-9.

29. Li SY, Wang TJ, Vivienne Wu SF, Liang SY, Tung HH. Efficacy of controlling night-time noise and activities to improve patients' sleep quality in a surgical intensive care unit. J Clin Nurs 2011;20:396-407.

30. Norton C, Flood D, Brittin A, Miles J. Improving sleep for patients in acute hospitals. Nurs Stand 2015; 29:35-42.

31. DuBose JR, Hadi K. Improving inpatient environments to support patient sleep. Int J Qual Health Care 2016;28:540-53.

32. Wallace CJ, Robins J, Alvord LS, Walker JM. The effect of earplugs on sleep measures during exposure to simulated intensive care unit noise. Am J Crit Care 1999;8:210- 8.

33. Huang HW, Zheng BL, Jiang L, Lin ZT, Zhang GB, Shen L, Xi XM. Effect of oral melatonin and wearing earplugs and eye masks on nocturnal sleep in healthy subjects in a simulated intensive care unit environment: which might be a more promising strategy for ICU sleep deprivation? Crit Care 2015;19:124.

34. Hu RF, liang XY, Zeng YM, Chen XY, Zhang YH. Effects of earplugs and eye masks on nocturnal sleep, melatonin and cortisol in a simulated intensive care unit environment. Crit Care 2010;14:66. 
35. Elliott RM, McKinley S, Cistulli P, Fien M. Characterisation of sleep in intensive care using 24-hour polysomnography: an observational study. Crit Care 2013;17:46.

36. Boyko Y, Jennum P, Nikolic M, Holst R, Oerding H, Toft P. Sleep in intensive care unit: The role of environment. J Crit Care 2017;37:99-105.

37. Freedman NS, Gazendam J, Levan L, Pack AL, Schwab AL. Abnormal sleep/wake cycles and the effect of environmental noise on sleep disruption in the intensive care unit. Am J Respir Crit Care Med 2001;163:451-7.

38. Gabor JY, Cooper AB, Crombach SA, Lee B, Kadikar N, Bettger HE, Hanly PJ. Contribution of the intensive care unit environment to sleep disruption in mechanically ventilated patients and healthy subjects. Am J Respir Crit Care Med 2003;167:708-15.

39. Darbyshire J, Young JD. An investigation of sound levels on intensive care units with reference to the WHO guidelines. Crit Care 2013;17:187.

40. Litton E, Carnegie V, Elliott R, Webb SA. The efficacy of earplugs as a sleep hygiene strategy for reducing delirium in ICU: a systematic review and meta-analysis. Crit Care Med 2016;44:992-9.

41. Schwab KE, Ronish B, Needham DM, To AQ, Martin JL, Kamdar BB. Actigraphy to evaluate sleep in the intensive care unit: a systematic review. Ann Am Thorac Soc 2018;15:1075-82.

42. Le Guen M, Nicolas-Robin A, Lebard C, Arnulf I, Langeron O. Earplugs and eye masks vs routine care prevent sleep impairment in postanaesthesia care unit: a randomized study. $\mathrm{Br}$ J Anaesth 2014;112: 89-95.

43. Sadeh $A$. The role and validity of actigraphy in sleep medicine: an update. Sleep Med Rev 2011;15:259-67.

44. Van de Water AT, Holmes A, Hurley DA. Objective measurements of sleep for non-laboratory settings as alternatives to polysomnography - a systematic review. J Sleep Res 2011;20:183-200.
45. van der Kooi AW, Tulen JH, van Eijk MM, de Weerd AW, van Uitert MJ, van Munster BC, Slooter AJ. Sleep monitoring by actigraphy in shortstay ICU patients. Crit Care Nurs Q 2013;36:169-73.

46. Beecroft JM, Ward M, Younes M, Crombach S, Smith O, Hanly PJ. Sleep monitoring in the intensive care unit: comparison of nurse assessment, actigraphy and polysomnography. Intensive Care Med 2008;34:2076-83.

47. Darbyshire JL, Borthwick M, Edmonds P, Vollam S, Hinton L, Young JD. Measuring sleep in the intensive care unit: electroencephalogram, actigraphy, or questionnaire? J Intensive Care Soc 2020;21:22-7.

48. Kamdar BB, Kadden DJ, Vangala S, Elashoff DA, Ong MK, Martin JL, Needham DM. Feasibility of continuous actigraphy in patients in a medical intensive care unit. Am J Crit Care 2017;26:329-35.

49. Grap MJ, Borchers CT, Munro CL, Elswick RK, Sessler CN. Actigraphy in the critically ill: correlation with activity, agitation, and sedation. Am J Crit Care 2005;14:52-60.

50. Kroon K, West S. 'Appears to have slept well': assessing sleep in an acute care setting. Contemp Nurse 2000;9:284-94.

51. Macfarlane $M$, Rajapakse $S$, Loughran $S$. What prevents patients sleeping on an acute medical ward? An actigraphy and qualitative sleep study. Sleep Health 2019;5:666-9.

52. Naik RD, Gupta K, Soneja M, Elavarasi A, Sreenivas V, Sinha S. Sleep quality and quantity in intensive care unit patients: a cross-sectional study. Indian J Crit Care Med 2018;22:408-14.

53. Altman MT, Knauert MP, Pisani MA. Sleep disturbance after hospitalization and critical illness: a systematic review. Ann Am Thorac Soc 2017; 14:1457-68.

54. Wilcox ME, Rubenfeld GD, Walczak KD, Black SE, McAndrews MP, Lim AS. Actigraphic measures of sleep on the wards after ICU discharge. J Crit Care 2019;54:163-9. 